This PDF is a selection from an out-of-print volume from the National Bureau of Economic Research

Volume Title: The Rate and Direction of Inventive Activity: Economic and Social Factors

Volume Author/Editor: Universities-National Bureau Committee for Economic Research, Committee on Economic Growth of the Social Science Research Council

Volume Publisher: Princeton University Press

Volume ISBN: 0-87014-304-2

Volume URL: http://www.nber.org/books/univ62-1

Publication Date: 1962

Chapter Title: Some Society-Wide Research and Development Institutions

Chapter Author: Robert Merrill

Chapter URL: http://www.nber.org/chapters/c2135

Chapter pages in book: (p. 409 - 440) 


\title{
Some Society-Wide \\ Research and Development Institutions
}

\author{
ROBERT S. MERRILL \\ UNIVERSITY OF MINNESOTA
}

THIS paper is concerned with institutional or organizational determinants of directions of research and development activity. In Western industrial societies, $\mathrm{R}$ and $\mathrm{D}$ of many kinds is carried out in a variety of different society-wide institutional settings. For example, the National Science Foundation distinguishes four major R and D sectors: industry; colleges and universities; other nonprofit institutions; and federal government agencies. In addition, each of these sectors includes several subsystems. If we want to understand the determinants of directions of $\mathrm{R}$ and $\mathrm{D}$, we need to understand how these different institutional systems operate and how they are interrelated to form an overall system.

With the recent increase of interest in $R$ and $D$ has come a considerable increase in quantitative data about $R$ and $D$ and in descriptions of relevant institutions. But, except for work on industrial $R$ and $D$ making use of economic theory, ${ }^{1}$ there seems to be relatively little effort to formulate systematic notions about how the institutional subsystems operate. It seems to me that even crude "models" of the other R and D subsystems would serve two useful functions at this stage of our study. They would serve as guides in selecting important questions for empirical research. And they would serve as a basis for developing more rigorous and sophisticated theories.

The particular aim of this paper is to present some preliminary ideas about the workings of four R and D subsystems: "pure" academic natural science research, academic medical research, academic engineering research, and government agricultural research. These were chosen because they differ from one another and from the market-patent system. Therefore, they may suggest something of the

NoTE: I want to thank Jacob Schmookler, Scott Maynes and, especially, Joseph Spengler for helpful comments on earlier drafts of this paper. The defects remaining are mine alone. Much of the work was done while at the Research Center in Economic Development and Cultural Change, the University of Chicago.

${ }^{1}$ Richard R. Nelson, "The Economics of Invention: A Survey of the Literature," Journal of Business, Vol. 32, 1959, pp. 101-127 and, by the same author, "The Simple Economics of Basic Scientific Research," Journal of Political Economy,Vol. 67, 1959, pp. 297-306. 
variety of the institutional arrangements which affect $R$ and $D$. The sketches are presented as hypotheses, not proven facts, and preliminary hypotheses at that.

Certain limitations of the discussion need to be mentioned at the outset. First, my concern is with determinants of directions of $\mathbf{R}$ and $D$ activity within each subsystem. No effort is made to discuss the factors which influence the total amount of funds made available to each subsystem. Second, 1 have made the assumption that the outside groups and organizations that finance much of the research in the academic subsystems discussed do not have major net effects on the directions of research within these systems. This begs a question which is the subject of considerable contemporary debate, especially with reference to government financing. However, I believe the assumption is a useful first approximation. Moreover, I think improving our understanding of the internal workings of the academic subsystems is a necessary step in developing ways of empirically determining the role of outside subsidizers.

\section{Academic Science Research}

The first example of a society-wide R and D subsystem I would like to discuss is that of "pure" or theoretical natural science research as carried out in universities. The distinguishing feature of "pure" scientific research is the aim of advancing knowledge and gaining deeper understanding for its own sake. More work has probably been done on developing a picture of how academic science functions as a system than on any other nonindustrial $R$ and $D$ subsystem. This provides exceedingly helpful guides. In particular, I am much indebted to Polanyi for many of the ideas used here. ${ }^{2}$

My procedure is first to outline some of the crucial features of the institutional setting of academic science. I then try to show, in a simplified way, how these features lead to an over-all pattern of allocation of personnel and resources among different lines of research within academic science. Next I discuss the particular content of the scientific values used in judging the scientific significance of substantive research work. Finally, I discuss factors that influence the production within academic science of knowledge useful as inputs to further research rather than as "final outputs."

\footnotetext{
${ }^{2}$ Michael Polanyi, Science, Faith and Society, Oxford, 1946; - - The Logic of Liberty, Chicago, 1951; - - Personal Knowledge, Chicago, 1958.
} 


\section{INSTITUTIONAL SETTING AND OPERATION}

Certain features of the university setting of academic science seem especially important in influencing directions of research. The first important feature is the acceptance by influential segments of modern Western societies of the idea that a major function of universities is the advancement of knowledge. In "national" universities, in which the great bulk of scientific research takes place, the faculty, the administrators, and the trustees are concerned with advancing the reputation of their institutions as centers of scientific and scholarly investigation. Departments in major universities are similarly concerned with their reputations, which depend primarily on the excellence of the research carried out by department members. For this reason, a major determinant of appointment and advancement in a science department is the publication of research of scientific significance.

A second major feature of the university setting is the fact that the accepted judges of the merit of published scientific research-of the extent to which it advances knowledge-are professional colleagues throughout the country (and abroad) and especially those "universally recognized as the most eminent." 3 Professional opinion and advice are relied on in making decisions about university appointments. ${ }^{4}$ Moreover, foundation and government research funds are usually allocated on the basis of advisory judgments by professional scientists concerning the probable scientific worth of research proposals submitted.

A final feature of importance is the freedom or autonomy granted the individual university faculty member to use the time he has available and the personnel and facilities he is able to obtain to conduct the research he wants to carry out.

These institutional features obviously influence the directions of academic science research. Their effect is to allocate personnel and resources among lines of research in a way that tends to "maximize" the expected scientific significance of the results obtained, subject to the constraints imposed by the availability of funds, personnel, and other resources. This effect is brought about in the following way.

Each academic scientist working in his specialty and motivated by a concern for his academic career if by nothing else, will pursue those

\footnotetext{
${ }^{3}$ Polanyi, The Logic of Liberty, p. 54.

4 See Eric Ashby, Technology and the Academics, London, 1958, for a good discussion of how university academic government works in the British Commonwealth.
} 
lines of research which he expects will yield the most significant results. Results are published and discussed, and their scientific merit evaluated by professional colleagues in the specialty. As reputations are established, academic departments, striving to enhance their standing in their disciplines, will try to appoint or promote those scientists pursuing especially successful lines of work. Scientists advising on the granting of fellowships and grants-in-aid will behave similarly. These actions perform a twofold function. They reinforce the goal of advancing knowledge by tangibly rewarding productive scientists with income, tenure, academic rank, prestige, and professional influence. In addition, departments trying to attract promising scientists will offer such advantages as increased time for research, access to more and better graduate students and technical assistants, better library and other research facilities, interested and competent colleagues, etc. Such competition within and between departments means that the more productive scientists in a specialty obtain better research conditions than do others. This tends to increase the output of scientifically significant results obtainable from given resources.

Similar forces within academic science shift resources between specialties within each discipline. Departments will tend to seek scientists in specialties that are yielding especially exciting results. In addition, graduate students will be attracted to such specialties. Established scientists in "active" specialties usually will be able to obtain more than average funds for supporting the training and research of graduate students. Moreover, they will be able to point to the wider career opportunities in such specialties as compared to those judged less promising. In these ways, trained personnel (and facilities) in a discipline are shifted toward those specialties which appear to be the most scientifically productive at a given time. Obviously, this also tends to increase the scientific significance of the research results obtained with the funds available to the discipline.

Finally, there are also forces in academic science that tend to in crease the proportion of research resources available to active disciplines as compared to that available to disciplines where work of less scientific promise is going on. Scientists of one discipline will tend to exaggerate its scientific importance relative to others, and there are obvious incentives for each discipline to try to obtain as large an amount of funds as possible. The resolution of these conflicting claims for research support, insofar as they are resolved within the system of academic science, falls on persons in positions where they need to 
consider the over-all scientific significance of different possible uses of resources-persons responsible for decisions affecting a whole division, school, college, or university. They have incentives to move resources to disciplines where work of high scientific significance appears possible. In addition, newcomers to academic science are more likely to select careers in rapidly advancing disciplines than in those that are comparatively stagnant.

All these institutional arrangements result in a system which tends to maximize the expected scientific value of the research done with available resources. The scientific value of research results is judged by scientists themselves and these judgments, operating through the institutions discussed, are the means by which the community of academic scientists governs itself. Insofar as this is true, it is clear that we need to understand the standards, criteria, preferences, or principles which are used by scientists in judging the scientific value of research proposals and results. ${ }^{5}$ On what basis are some results deemed important and exciting while others are judged to be insignificant and not worth following up? Working out ways of studying this question empirically appears to be a crucial step in advancing our knowledge of the determinants of the directions of academic science research. In the following section I want to discuss this aspect of the subsystem of academic science further.

\section{JUDGING SCIENTIFIC VALUE IN ACADEMIC SCIENCE}

Judgments of the scientific significance of research in academic science have certain general features that need to be kept in mind. First, there is great uncertainty in scientific research-it is really a search into the unknown. This means that judgments are tentative estimates or guesses which are needed in making decisions, even though they may turn out to be wrong after the fact. Second, the criteria or standards used in judging scientific research are largely implicit. Such explicit formulations as exist are maxims or pointers, not precise criteria that can be routinely applied by any appropriately trained person. It is generally recognized among scientists that some persons are far better judges than others. ${ }^{6}$ Third, even though there is a common core of values in the traditions of science to which scientists appeal in supporting their judgments, it is recognized that consensus is by no means

${ }^{5}$ To avoid misunderstanding, let me say that the term "value" is used here in the general sense of "utility" or "use value," and not, as is usual in economics, in the sense of exchange value or price.

${ }^{6}$ See Polanyi's remarks about Rutherford (Science, Faith and Society, pp. 76-77). 
always possible in particular cases. What one scientist thinks will be promising may be regarded as useless by others. When disagreements arise, scientists are formally free to follow their own judgment and attempt to demonstrate through further research the validity of their ideas.

All this puts the student who wants to understand the selection of directions of academic scientific research in a difficult position. Essentially his problem is to develop testable propositions about how directions of research vary with circumstances from qualitative information about the way scientists make judgments. In this section I want to discuss some of the criteria that seem to be operative in scientific decisions in an effort to suggest some of the kinds of systematic empirical research which would be useful in increasing our understanding of the directions taken by research in academic science.

We may begin by dividing judgments of the value of proposed or published scientific contributions into two kinds. On the one hand, there are judgments concerning the value of substantive contributions to science-direct contributions to knowledge of the subject matter under investigation. They are the scientific discoveries of empirical facts, regularities, concepts, and theories which take their place in the textbooks which summarize what is known. In addition to these "final outputs" of scientific research, there are other contributions whose significance lies primarily in their role as aids to further research. They serve primarily as knowledge "inputs" rather than as final outputs. Let us discuss these two kinds of evaluation, in order.

\section{Eraluation of Substantive Contributions}

I believe the most useful statement of the criteria used in judging substantive contributions in academic science is that of Michael Polanyi. ${ }^{7}$ Let us consider the criteria used to judge contributions on a given subject, and then discuss how findings in different fields may be compared.

Within a given subject-matter field, Polanyi thinks two criteria are of primary importance: (1) the precision, accuracy or certainty of a contribution; and (2) its systematic relevance or profundity - the breadth of its coverage and the variety of its implications. ${ }^{8}$ These

' Polanyi, The Logic of Liberty and Personal Knowledge. Schwab, dealing with a somewhat different problem, has developed an interesting set of distinctions which could also be used for this purpose (Joseph J. Schwab, "What Do Scientists Do?" Behavioral Science, Vol. 5, 1960, pp. 1-27).

${ }^{8}$ Polanyi, Personal Knowledge, pp. 135-136. 
criteria "apply jointly, so that deficiency in one is largely compensated for by excellence in the others." ${ }^{9}$ A contribution which is very accurate and reliable but very narrow in its scope may be valued as highly as a contribution which is less precise but more general. Such judgments are made on the basis of the knowledge available at the time. They may be drastically altered as a result of changes in the state of knowledge. Consider the precision measurement of atomic weights. ${ }^{10}$ At one time, the atomic weights of the elements were thought to be important clues to the basic nature of matter. Later, the discovery of isotopes showed that this was not so, that the important weights were isotopic masses. Precision work that was awarded a Nobel prize in 1914 was thought to be of little interest by 1932 .

The relative importance accorded these two values thus becomes an important factor affecting the directions of scientific research. Responses to new knowledge may provide a way of estimating the weight given these values. One would expect that in a discipline or scientific tradition which evaluated precision highly, research would change markedly in response to the discovery of new ways of achieving greater precision, but not shift very much with discoveries affecting the systematic relevance of findings. Conversely, in disciplines or traditions where systematic relevance is given the greater weight, an opposite pattern of response to changes in knowledge would be expected. Comparative studies of responses to the same or similar changes in knowledge should enable us to empirically document the role of these values in various fields of science. Moreover, such studies would provide tests of the extent to which these values account for the selection of lines of research in particular fields.

Let us now ask how contributions of equivalent precision and systematic relevance in different subject-matter fields are compared. Here, Polanyi thinks a third criterion operates, the criterion of "intrinsic interest." Some subjects are just more interesting than others, apart from any relation they may have to practical concerns. To quote Polanyi:

In science, as in ordinary perception, our attention is attracted by things that are useful or dangerous to us, even though they present themselves less distinctly and coherently. This sets up a competition between practical and theoretical interests. . . . But

- Ibid, p. 136.

${ }^{10}$ Ibid., p. 136. 
things are also interesting in themselves, and their intrinsic interest varies greatly. Living animals are more interesting than their dead bodies; a dog more interesting than a fly; a man more interesting than a dog. ${ }^{11}$

Thus, insofar as academic science is "pure" science, concerned with knowledge for its own sake, intrinsic interest is the guiding criterion in evaluating the scientific value of similar contributions to our knowledge of different subjects. We here encounter the long debated issue of the influence of practical or utilitarian values on directions of academic science research. Polanyi's distinction between practical and intrinsic interest in a subject suggests ways this problem might be studied empirically.

Polanyi appears to assume that everyone judges the intrinsic interest of various subjects in the same way. However, it seems likely that there are cultural and subcultural differences in the amount of intrinsic interest accorded particular subjects. But, if such cultural differences exist, it also seems probable that they would manifest themselves in relatively stable differences in the proportion of effort devoted to the same scientific subjects in different societies. Practical interests, on the contrary, can be expected to change rapidly even in a single society and to differ from society to society in ways that are correlated with extrascientific conditions which can be studied. Practical interest in particular military, agricultural, industrial, or medical problems certainly exhibit such variations. Therefore, it ought to be possible to study the role practical interests play in the selection of lines of research by studying empirically the extent to which directions of research vary and shift with differences and changes in conditions affecting practical interests. Such study is complicated by the fact that the state of knowledge, or what Cohen calls the scientific situation, ${ }^{12}$ also changes rapidly and, as we have seen, also affects directions of research. However, it should be possible to distinguish the effects of these different kinds of changes.

We thus have the picture of the "pure" scientific significance of substantive contributions to academic science being judged according to some weighted total of their precision, systematic relevance, and intrinsic interest. In addition, practical interests may also play a role in judging the value of research results. The possible role of practical

"Ibid., p. 138.

12 I. Bernard Cohen, Science, Servant of Man, Boston, 1948, pp. 31-32. 
interests raises another problem that requires explicit discussion. We have assumed so far that the only role practical interests play in academic science is possibly giving greater weight or importance to the scientific study of certain topics than they otherwise would have. We have assumed that practical interest in a subject does not alter the scientific character of the research done. However, it is relatively easy to show that practical interest in a subject can also alter the direction taken by the research. This possibility is clearly seen in industrial "basic research" in examples such as the following. Shell Development undertook a study of the mechanisms of hydrocarbon oxidation. ${ }^{13}$ This is a theoretical or scientific subject, but was picked because the phenomena were important in Shell operations. In the course of this work discoveries were made concerning the role of hydrogen peroxide. Since hydrogen peroxide was a commercially interesting substance, the focus of the research shifted to the study of reactions that would produce it in larger yields. That work, in turn, led to still other commercial production methods. Thus, even though the research apparently started out as a scientific study, it was really not that. Rather, it was a strategy for making inventions; a way of uncovering clues from which useful processes or products could be developed. Gershinowitz comments as follows:

In the large sense there can be no such thing as undirected research in industry. It may start out thus, but essentially it is directed into types of activity that the managers of that research laboratory have confidence will some time have application. Therefore, I think it is very important that there shall be somewhere a place in the research setup of the nation where really undirected investigation can take place. Here a man who is working on the kinetics of oxidation of hydrocarbons will not be distracted into studying the kinetics of reactions to make hydrogen peroxide. Here he will continue to work on what he began and let only the results of his own activities determine the direction he wants to go. ${ }^{14}$

In cases like this, practical interest in a scientific subject turns the investigation into a search for practically useful clues. This is not

${ }^{13}$ Harold Gershinowitz, "Industrial Research Methods and Industrial Research Programs as Affecting Academic Research," Changing Patterns of Academic Research, Sigma Xi, Rensselaer Chapter, Rensselaer Polytechnic Institute, 1957.

${ }^{14}$ lbid., p. 21. 
what Polanyi calls technically justified science, in which the aim is deeper understanding of a subject of practical interest. ${ }^{15}$ Instead it is a way of making inventions by doing enough scientific investigation to uncover useful new ideas which then become the center of attention. Such research ought to be called something like exploratory scienceinvention to distinguish it from technically justified science. Exploratory science-invention leads to some advances in general knowledge but these are likely to be limited, since work is continually diverted to the exploration of practical possibilities.

Thus, in examining the role of practical interests in academic science, we need to know how such interests affect the relative amount of work done in various subject-matter fields and the extent to which research becomes exploratory science-invention instead of technically justified science. How much exploratory science-invention is carried out in academic science will depend on a number of institutional factors. It will depend, for example, on the extent to which investigators are rewarded for advancing scientific knowledge, apart from any useful clues they may uncover, as compared with the attention given findings of direct practical relevance. It will also depend on how committed researchers are to a scientific career. If an academic chemist, for example, is not strongly committed to science, he may select lines of research that promise practically significant findings which would make him an attractive employee in industrial research.

It seems clear that unless the community of academic scientists is strongly committed to the importance of advancing knowledge and is supported in this commitment by significant segments of the larger society, this goal will not be fully affective in guiding the direction of research. It is possible, for example, that the apparently greater value placed on the humanistic search for truth and the academic life in Europe as compared to the United States has something to do with the apparently greater output of high quality science there. There certainly is evidence that it is very difficult to transplant academic science effectively to countries where its values and traditions are not understood. ${ }^{16}$ Careful comparative study of the attention devoted to selected lines of research in different countries might enable us to document and test empirically these impressions.

${ }^{15}$ Polanyi, Personal Knowledge, p. 179.

${ }^{16}$ Ibid., p. 182; also Polanyi, The Logic of Liberty, p. 56. 


\section{Knowledge Capital in Academic Science}

So far we have discussed only standards used to evaluate substantive contributions as final outputs of academic science research. But research also produces kinds of knowledge whose significance does not lie in their contribution to knowledge of the subject being investigated but rather in the usefulness of such knowledge in undertaking further research. This is true of the development of new scientific instruments such as the cyclotron; of new methods of chemical analysis, physical measurement, or observation; of new methods of experimental design, manipulation, and control, and so on. Moreover, certain kinds of background research produce knowledge which is chiefly useful as an aid to research. ${ }^{17}$ Cohen mentions the usefulness in organic analysis and synthesis of the vast collection of data on melting and boiling points and similar properties of countless organic compounds. ${ }^{18}$

Knowledge that is useful as an input to further research can be thought of as knowledge capital. An addition to the stock of knowledge capital aids further research by opening up new possibilities or by reducing the cost or time required to explore already existing possibilities. From this point of view, it is clear that substantive contributions can serve as knowledge capital as well as final outputs. Fruitful substantive contributions are precisely those which seem to open up new significant research possibilities.

All of this means that to understand the selection of directions of academic science research we must understand how the capital value as well as the substantive value of research results are judged. The basic logic used goes something like this. First, an effort is made to estimate the net additions to substantive knowledge which are likely to be produced in the forseeable future as a result of the knowledge capital contribution being evaluated. Then the scientific significance of these expected additions is estimated and imputed to the knowledge capital and to the research that produced it. In other words, an effort is made to judge the significance of an addition to knowledge capital by estimating its expected net effect on the output of substantive scientific results in the near future. It is obvious that such estimates are difficult to make, that scientists will often disagree, and that the estimates will often turn out to be wrong. But at least rough judgments

${ }^{17}$ Cohen, op. cit., p. 53.

${ }^{18}$ Ibid., p. 252. 
have to be made if work on scientifically useful aids to research is to be promoted, and a reasonable guess is better than nothing at all. Furthermore, as time goes on and the impact of a given piece of research can be assessed on the basis of more evidence, evaluations of additions to knowledge capital can be corrected and the rewards to scientists producing them changed accordingly.

It follows from this argument that the producer of knowledge capital as well as the producer of results of substantive significance will tend to benefit privately according to the social benefits to science which stem from his work. Within the subsystem of academic science there appears to be no external economy problem comparable to that which Nelson has pointed out in the case of "basic" research carried out by firms in a market-patent system. ${ }^{19}$ Probably the best way to test these notions empirically and to increase our knowledge of the determinants of research devoted to the production of knowledge capital would be to compare work on similar research aids in academic science and other subsystems such as private industrial research.

\section{CONCLUSIONS}

If the preceeding picture of the way the subsystem of academic science operates is a useful first approximation, it suggests that a key problem in understanding the selection of directions of scientific research is obtaining better knowledge of the scientific values or criteria used in making professional evaluations of the significance of different lines of research. This seems to require the study of the way decisions vary with differences in relevant circumstances such as the state of knowledge, practical interests, institutional organization, etc. The discussion attempted to suggest ideas which would be useful in the design of such research.

\section{Academic Medical Research}

I now turn to some of the $\mathrm{R}$ and $\mathrm{D}$ subsystems devoted to the improvement of practical arts. Practical arts are concerned with the achievement of useful results. It is usefulness in actual practice under a particular set of prevailing conditions relative to available alternatives that is the basic test of advances in a practical art. Meeting such specifications gives to technology and its improvement a character and complexity significantly different from that of pure science. However, in the absence of a really adequate analysis of the kinds of

${ }^{19}$ Nelson, "The Simple Economics of Basic Scientific Research." 
knowledge involved in the improvement of a practical art, the following discussion will be limited to features that emerge in making broad institutional comparisons.

The first example of a $\mathrm{R}$ and $\mathrm{D}$ subsystem devoted to improving the practical arts to be considered is academic medical research. By academic medical research I mean the research activities of full-time or part-time staff members of medical schools and teaching or other hospitals who, in addition to teaching and often providing medical services, also engage in medical research. Included is a broad spectrum of $\mathrm{R}$ and $\mathrm{D}$ activities. They range from clinical research concerned with the introduction, testing, and improvement of specific advances in medical practice on through experimental and clinical studies devoted to uncovering useful new leads, to the research carried out in the so-called preclinical medical sciences such as anatomy, physiology, bacteriology, biochemistry, etc.

Let us first examine some of the important features of the institutional organization of academic medical research to see what clues we can get concerning determinants of the direction of research activity in this subsystem. To a considerable degree, the institutional arrangements are like those of academic science. First, academic medical research is largely subsidized from outside the system in the same ways that academic science is. Second, the prestige of medical schools and associated institutions depends to a considerable extent on the reputation they build up as contributors to the advancement of the medical arts and sciences. Third, donors of funds and administrators generally defer to professional judgments of the value of medical research results and follow medical advice in the allocation of funds. Fourth, established academic medical investigators are given autonomy to decide what lines of research they want to pursue with the means they are able to obtain. Therefore, persons following a research career in medicine are in a situation where they have incentives to do research that will be considered significant by professional opinion.

However, some workers in academic medical research are in an institutional position that differs significantly from that of the typical academic pure scientist. It appears that many of the positions in clinical departments in medical schools and teaching hospitals are part-time positions or positions in which the incumbent is allowed to practice for fees and to retain at least a portion of the fees earned. ${ }^{20}$

${ }^{20}$ Medical Research: A Midcentury Survey, Boston, Little, Brown for the American Foundation, 1955, Vol. 1, pp. $214 \mathrm{ff}$. 
Anyone thus employed has a stake in a private practice and is not necessarily committed solely to a research career. So long as he performs his official functions well enough to retain his position, it is possible for him to orient his research along lines significant for his practice. He could focus his work on attempts to make improvements in medical practice that would enhance his reputation as a practitioner and thus his income derived from practice. Such economic incentives could operate even if, as is the case in medicine, professional standards dictate prompt and full publication of research findings and open access to the knowledge and use of new techniques. A reputation as an originator and longer experience with a new procedure may attract fee paying patients even when an innovation has become widely diffused. Similar incentives to direct research toward improvements which attract fee paying patients could also operate on an institutional level. Clinics, out-patient departments, and hospitals affiliated with medical schools may seek to attract patients who will improve their budgetary position, and research workers associated with such institutions could be given incentives to direct their activities in such directions also.

Within the constraints that regulate access to medical research funds and positions and that control medical practice, there is probably a certain amount of academic medical research oriented toward the financial benefit of the investigator or the institution with which he is affiliated. The extent and significance of such influences on the selection of lines of research can only be ascertained when methods have been developed for distinguishing such research from that selected on other bases. Crucial to such study would be a determination of the kinds of medical advances that attract financially rewarding patients and the kinds of improvements that have no significant effect of this sort. That distinction would provide a framework for detailed empirical study to see what effect, if any, this difference has on the allocation of effort to lines of research.

My impression is that most academic medical research is focused on obtaining results that will be judged highly by the profession and not on direct financial gain. In this context the key question is what criteria are used to judge the medical significance and value of advances in the medical arts and sciences. Two general possibilities suggest themselves. On the one hand, the traditions of medicine are those of a service profession devoted to meeting the medical needs of the people it serves. Insofar as these traditions govern the evaluation of 
research, medical advances would be judged according to their significance in meeting the medical needs of society. On the other hand, given the position of academic medical research as a major research arm of a profession whose practitioners obtain income by providing services to the public, there is the possibility that medical advances could be judged according to their significance in economically benefiting the profession as a whole. I doubt whether the economic criterion is very significant. It is difficult to see how most medical advances significantly increase the average income of the medical profession. Professional policies in other areas, such as those affecting the number of medical practitioners, seem much more important. Furthermore, pressures from the lay public and from subsidizers of medical research tend to reinforce the traditions within medicine stressing the preeminence of meeting the medical needs of the public. It therefore appears likely that professional standards for judging the significance of advances in medical knowledge stress the extent to which advances enhance the ability of the profession to meet its social obligations.

The question then becomes, what professional criteria are used to judge the extent to which an improvement helps in meeting public medical needs? A number of criteria are often mentioned in this connection, such as amount of reduction in mortality rates, in morbidity rates, in average duration of illness, in severity of aftereffects, in amount of suffering, and so forth. These and other more specific criteria appear to derive from general social values in Western societies. However, so far as I know, little study has been made of how these criteria or others are used in professional medical judgments of improvements in the art. In particular, we do not know the relative weights given various criteria in reaching over-all judgments. There is evidence of the use of the kinds of criteria mentioned. For example, the Steelman report which is based, at least in part, on professional medical advice includes the following statement: ". . . if the Federal Government is financing a broad program of medical research, the problems under investigation should bear a reasonably close relation to those causes of illness and death which are most common in the population and in which the public, therefore, has the greatest stake."21

How far and in what ways such criteria guide professional judgments and decisions concerning directions of academic medical

${ }^{21}$ John R. Steelman, The Nation's Medical Research, Vol. 5 of Science and Public Policy, Washington, 1947, p. 86. 
research are questions clearly needing study. In modern times, due to demographic changes and to changes in the medical arts themselves, the importance of various diseases as causes of illness, death, suffering, etc. has often changed radically. Systematic empirical study of the effects of such changes on the directions of academic medical research ought to shed considerable light on what criteria are used and the relative importance accorded different indices of medical need. In such a study, the effect of changes in medical knowledge on expected costs of making comparable advances in different medical fields would have to be taken into account. One would not expect that resources would be allocated to research on diseases in direct proportion to the severity of the medical problems they present. Such an allocation would not take into account differences in the expected difficulty and cost of making comparable improvements in the prevention or treatment of different diseases. Expected costs obviously vary greatly from disease to disease and change as the state of medical knowledge changes. These facts complicate the study of the criteria used to evaluate the importance of different lines of academic medical research, but I doubt if the difficulties are insurmountable.

The professional standards and values used to judge the probable medical importance of specific advances in medical practice can be used directly in making decisions about the importance of research on particular medical problems. They can also be used to evaluate alternative lines of exploratory science-invention. The question of the allocation of resources to technically justified medical sciences and to fields within them seems to me to raise additional issues. I suspect empirical study would show that much of the academic medical research within the preclinical disciplines (e.g. anatomy, physiology, biochemistry, and even bacteriology, pathology, and pharmacology) is carried out as technically justified science. That is to say, much of the research in these fields is concentrated on gaining a deeper general understanding of the subjects studied and not on obtaining clues of direct practical significance. These fields are professionally organized, have their own journals, and their own foci of interest. We should be able to test this guess by studying how directions of research in the preclinical medical sciences vary in response to changes in knowledge opening up new lines of scientific study as compared with their response to changes in the importance of practical medical problems related to their subject matter fields.

If the preclinical medical disciplines do function to a considerable 
extent as technically justified sciences, how do we account for their elaborate development and for their ability to maintain a strongly scientific as against a practical orientation? Theoretically, one might argue that research in these fields is supported on the basis of some estimate of the average long-run rate of production of knowledge of practical medical significance; and that their scientific orientation is supported as a necessary condition for obtaining the particular kind of practically significant knowledge they produce. Nowadays many of the arguments for supporting basic research, including academic science, are of this sort.

However, the difficulty so often encountered in practical fields in generating support for activities that produce long-run, uncertain, broad, and difficult-to-trace benefits suggests that additional factors are involved. One possibility is that part of the support is based on the intrinsic interest of the phenomena studied in the medical sciences. This possibility could be explored by detailed study of the attention paid to specific topics relative to the prospects of practically significant findings and the prospects of precise and systematically coherent results. A major sign of intrinsic interest in a subject is support of research on it in the absence of practical implications and in the face of inability to produce as precise or profound findings as are possible in other fields. In addition, it seems probable that there has developed within medicine and among groups concerned with the support of medical research the conviction that scientific understanding of the art is a good thing in the long run for the profession, apart from any effort to assess practical benefits relative to costs. Wide variations appear to exist among the practical arts in the importance attached to understanding of the scientific principles involved. Though such variations may reflect the different practical benefits derived from advances in related scientific knowledge, I doubt if this fully accounts for the facts. Systematic comparison of the development of technically justified science research auxiliary to medicine with that related to agriculture, mining, metal working and other industrial fields would shed light on this question.

To sum up, the subsystem of academic medical research as a system for improving a practical art appears to have a number of distinctive characteristics. For example, it differs from industrial research in its orientation toward meeting medical needs rather than market demand; in its open publication of findings; in the absence of intraindustry external economy problems; and in the development of 
special traditions supporting technically justified medical sciences. The reality of these characteristics and their effects on directions of research could be studied most directly in cases where similar kinds of medical research are carried out both within the academic subsystem and by pharmaceutical houses and surgical or other medical supply firms.

\section{Academic Engineering Research}

In this section I want to discuss only one question concerning academic engineering research suggested by comparisons with academic medical research. By academic engineering research I mean the research carried out in engineering schools, institutes of technology and related applied science departments. Unlike the situation in medicine, by far the largest amount of research on specific practical problems in engineering is done by firms operating in the marketpatent system. ${ }^{22}$ Despite this fact, it appears that technically justified engineering sciences receive less academic support than comparable medical sciences. An exploration of this problem may provide leads concerning additional institutional factors affecting research in $\mathbf{R}$ and $\mathrm{D}$ subsystems concerned with the improvement of practical arts.

Finch provides an interesting summary of the difference between academic medical and engineering research in the United States:

In engineering, as in the case of medicine, the work of natural scientists has never provided all the scientific knowledge and understandings which are essential to continued professional growth. In engineering the practical mechanics of heat (engineering thermodynamics), of electrical machines and circuits, of liquids and gases (hydraulics and fluid mechanics), of solids (elasticity and strength of materials), more recently of soils, foundations, and earth structures (soil mechanics) - all these and other basic engineering studies were, over a century ago, designated by the Germans as engineering science. They were based to be sure on the facts of natural science, but they have been developed by engineers in directions, scope, and understandings which would not claim the interest, time, and efforts of workers in pure science. Exactly the same situation has existed in the medical field, but here the scope, function, and importance of medical

${ }^{22}$ For a review of work on industrial research see Nelson, "The Economics of Invention: A Survey of the Literature." 
science is well understood and fully recognized. American engineering, on the other hand, faces today the task of making equally clear the place and importance in technological progress of research in engineering science. ${ }^{23}$

A corollary of this underemphasis on engineering science in U.S. academic engineering research is a greater emphasis than one might expect on specific practical problems like those dealt with in industry and on the study of such problems in an empirical, practically oriented way. Let me again quote Finch:

... many problems of engineering research involve the study and analysis of various forms, devices, structural or machine units, as well as a scientific explanation for physical, chemical, or other phenomena encountered in engineering practice. These are not necessarily development or industrial research problems, though they may arise in the activities of industry. . . . Unfortunately, however, such activities can very easily deteriorate into mere routine testing or empirical formula or coefficient hunting which may have little or no value in extending the frontiers of engineering knowledge and should seldom be referred to as research. ${ }^{24}$

There is still other evidence that U.S. academic engineering research has tended to be empirically rather than theoretically oriented. There is historical evidence that we borrowed from Europe when engineering practice itself required increased use of theoretically based methods. Finch notes:

Just before World War I some German books on stress analysis and similar subjects began to attract special attention. But the fact that the state of American engineering science was not all it should be and that American engineers were ill prepared to cope with the new problems which were becoming of importance is reflected very clearly in the rapid rise to prominence of numerous newcomers to our shores whose education had been acquired in Europe. ${ }^{25}$

My impression is that Europeans continue to play a significant

${ }^{23}$ James Kip Finch, Engineering and Western Civilization, New York, 1951, p. 315.

${ }^{24}$ Finch, Trends in Engineering Education, New York, 1948, pp. 89-90.

${ }^{25}$ Finch, Trends in Engineering Education, p. 19. 
role in the more theoretical aspects of academic engineering teaching and research. Finally, it may be noted that the increased importance of theoretical knowledge in engineering since World War II has resulted in a marked increase in the employment of mathematicians and physicists by industry for both $\mathrm{R}$ and $\mathrm{D}$ and engineering practice. This suggests that academic engineering training and research continues to lag behind the needs of practice.

The question then arises: what factors in the organization of U.S. academic engineering account for this apparent underemphasis on research in the engineering sciences? Two contributing factors may be suggested. One is the stress academic engineering institutions place on their function of providing services to local industry. Another possibility is that professional standards in U.S. academic engineering, outside a few research oriented institutions, stress the importance of immediately useful research results rather than more theoretical advances. It has been said that the practical orientation of U.S. engineering stemmed from a situation where the high cost of labor relative to other costs resulted in a lack of emphasis on economical use of materials and on precision of design. ${ }^{26}$ Though the problems of engineering practice have been changing and are now changing even faster, ${ }^{27}$ traditions based on the early situation have apparently altered more slowly.

Another factor involved lies in the area of relations between academic engineering and academic science. Wickenden describes the efforts of German technical schools to obtain academic status comparable to that of other scientific institutions and to obtain the right to grant a fully recognized research doctorate. ${ }^{28}$ This effort to establish fundamental research on technical subjects as a way of gaining stature in the academic world apparently had much to do with the development of the engineering sciences in Germany. Similar theoretical research interests on the part of academically trained engineers are reported for England ${ }^{29}$ and Europe generally. ${ }^{30}$ Though that interest

${ }^{26}$ Ibid., p. 13.

${ }^{27}$ See, for example, Arthur R. von Hippel, Molecular Science and Molecular Engineering, New York, 1959.

${ }^{28}$ W. E. Wickenden, A Comparative Study of Engineering Education in the United States and Europe, Society for the Promotion of Engineering Education, Bulletin No. 16, 1929.

${ }^{29}$ R. L. Meier, "Research as a Social Process," British Journal of Sociology, Vol, 2, 1951, pp. 91-104.

${ }^{30}$ The Organization of Applied Research in Europe, The United States and Canada, Vol. I, $A$ Comparative Study, Organization for European Economic Co-operation, Paris, 1954. 
may have adverse effects on the practicality of the work done on industrial problems (see above references), it undoubtedly contributes to the development of technically justified engineering sciences. In the cases cited, the concern of academic engineering groups with their general academic status apparently stems from the stronger humanistic interests and the higher status of scholarship prevalent in Europe as compared with the United States.

We need to work out ways of testing empirically such impressions concerning the possible effects of differences in academic engineering traditions on the directions taken by academic engineering $R$ and $D$. Empirical comparisons of the attention devoted to engineering sciences in different countries could be made. Differences between fields within engineering, such as the older and newer fields, ${ }^{31}$ need to be explored. Such studies would give us a basis for judging empirically the magnitude and nature of the differences in emphasis in various spheres of academic engineering research. We would then be in a position to study systematically the organizational, cultural, and other factors influencing $\mathbf{R}$ and $\mathbf{D}$ decisions in academic engineering.

\section{Government Agricultural Research}

I now turn to a different kind of $\mathbf{R}$ and $\mathrm{D}$ subsystem organized and operating in a governmental rather than an academic setting. The example chosen is governmental agricultural research as carried out by the U.S. Department of Agriculture and State agricultural experiment stations. ${ }^{32}$ Like academic engineering; governmental agricultural research services an industry operating in the price-market system. However, in contrast to industrial firms, agricultural operators carry out comparatively little research of their own so that government research constitutes the major source of agricultural $R$ and $D$ except in agricultural machinery and equipment, fertilizers, and insecticides and so on, where industrial firms also play a role.

The directions taken by government agricultural research are influenced by the organizational setting in which the research agencies operate. The research units in the USDA are divisions within a

${ }^{31}$ W. Rupert Maclaurin, "Technological Progress in Some American Industries," American Economic Review, 1954, pp. 182-184.

${ }^{32}$ For general background see: Carleton R. Ball, Federal, State and Local Administrative Relationships in Agriculture, Berkeley, 1938; A. Hunter Dupree, Science in the Federal Government, Cambridge, 1957; Alfred Charles True, A History of Agricultural Experimentation and Research in the United States 1607-1925, U.S. Dept. of Agriculture, Misc. publ. 25I, 1937. 
hierarchically organized federal government department while the state experiment stations are state government agencies administered by directors. It seems reasonable to assume that the heads of these units, like the heads of most governmental agencies, are in a situation where their own careers and their opportunities for performing public services which they feel are important depend on their ability to maintain and preferably to expand both the financial support and the tasks assigned to their organizations. Government agencies are usually concerned with developing that kind of support and influence which is helpful both in the bargaining within and between government departments during the budget making period and in the political processes of getting legislative support for their programs and the appropriation of funds to finance them. Fundamental to this objective is the political support of sizeable, politically influential segments of the relevant electorate and their elected representatives.

A major way government agencies that provide services to a clientele can develop public support is to supply especially desired services, as agricultural research strongly oriented towards the needs of farmers. Presumably, the main type of benefits desired by farmers from research agencies are services that help them economically through increasing their incomes. Therefore, government agricultural research organizations will probably seek to maximize the economic benefits to the industry of the work they are able to do within the budgetary, administrative, and legislative constraints under which they operate. T. W. Schultz, for example, argues that:

Undoubtedly other tastes and preferences, other than a "maximization" of economic value of the output enter into the decision relations determining the director's choices. However, even a casual look at the behavior patterns of directors in approving research projects suggests that economic considerations, broadly conceived and when taken over a span of years, are of primary importance. $^{33}$

In addition, Schultz characterizes the results in the following way:

The political mechanism does not cut with a razor's edge; it is a blunt contraption at best; and yet, it appears that in making

${ }^{33}$ Theodore W. Schultz, The Economic Organization of Agriculture, New York, 1953, p. 113. 
funds available for agricultural research, with all its imperfections, it compares favorably, for example, with the public and private efforts that went into the settlement of the American frontier. ${ }^{34}$

If the organization of government agricultural research can be approximated by some such model, then certain consequences for the way this $R$ and $D$ subsystem functions may be noted. Since research is supported by public funds, research findings are made freely available to the public not only as information (as in the case of patents) but also for use in practice by all farmers and farm firms. Furthermore, such agencies have strong incentives to communicate their results fully and promptly and also to be sure that the results are accurate and reliable. Competition among agencies, concern of researchers for their careers, and the checks provided by farmers who use recommended practices all tend to discipline the communication of results more effectively than is the case when results are made available in the form of patent claims. ${ }^{35}$ Further, the position of the agencies enables them to benefit (in the form of political support) from broadly useful improvements they develop, whether patentable or not. Thus, in their decisions about prospective benefits of lines of research, they are able to take into account the social benefits of intraagricultural (or at least intrastate intraagricultural) external economies in a way that firms in a market-patent system are not able to do ${ }^{36}$ In these ways, the system of government agricultural research works like that of academic medical research and differs from that of private industrial research.

Government agricultural research, however, also differs from academic medical research in ways that influence the directions of $\mathrm{R}$ and $\mathrm{D}$ activity. In the first place, practical benefits to agriculture are defined in essentially economic market oriented terms (subject to the modifications resulting from strong governmental regulation and subsidy) rather than in professional terms reflecting general social values operating outside the market expression of consumer demand. In short, government agricultural research services an industry operating in a regulated price-market system, not a service profession like medicine which tends to provide services on a need

${ }^{34}$ Ibid., p. 118.

${ }^{35}$ On patents see the remarks of James B. Conant in Science and Common Sense, New Haven, 1951, p. 331.

${ }^{38}$ Cf. Nelson, "The Simple Economics of Basic Scientific Research." 
basis. In the second place, the socially or politically expressed demands of the clientele on investigators appear to differ significantly in the two research fields. In the case of medical needs, lay members of society may express their interest in the solution of various medical problems, but beyond that they generally defer to professional opinion in decisions about what specific kinds of research ought to be done. The situation appears to be different in agriculture. Many farmers are skilled and often professionally trained practitioners of the arts of agriculture; they are analogous to practicing physicians rather than to patients. Therefore, they are likely to believe that they can evaluate the significance of particular agricultural problems and decide the kinds of research needed. They are likely to express their demands for research services in highly specific terms. The result is that government agricultural agencies may be forced to carry out the research farmers think will benefit them most, rather than follow professional judgments based on a wider acquaintance with scientific, technological, economic, and other developments affecting agriculture.

Other features of the standards or criteria farmers use to evaluate the research results provided them are also significant. It makes a difference, for example, whether farmers judge the economic benefits of research on the basis of results derived from recently received and used improvements or on the basis of results obtained over a longer period of time. If research directors feel that support for their work depends on their responding immediately to each new crisis or problem that arises, their choice of lines of research will be largely limited to specific projects capable of yielding benefits quickly. They will be in a position analogous to that of business firms fighting for survival who direct their $\mathbf{R}$ and $\mathbf{D}$ toward immediately useful improvements. If, on the other hand, farmers realize the benefits of longer-term lines of investigation on major unsolved problems, then research directors are in a position where the politically feasible alternatives among which they can choose are significantly broadened.

The support of long-term research would appear to depend on the extent to which agricultural interests defer to the expert judgment of investigators or defer to people in their own ranks who have made it their business to become informed about the issues involved in decisions about directions of agricultural research. This will also affect expenditures of funds on activities producing knowledge capital, such as work on improving research techniques and instruments; on making fundamental scientific advances in practically important 
fields not otherwise supported; and on building up bodies of broadly useful background data.

Thus, the operation of the subsystem of government agricultural research depends significantly not only on the internal organization of the system and on the arrangements affecting the way its clientele can influence research decisions, but also on the set of standards and beliefs that guide farmers in the exercise of their powers.

So far as I know, little systematic empirical research has been done on the facets of government agricultural research discussed here, though there appear to be a number of possibilities. The role of economic conditions in affecting the selection of directions of research could be studied by making interregional, intertemporal and even international comparisons of responses to various economic and other conditions. In addition, there are possibilities for comparisons between different $\mathbf{R}$ and $\mathrm{D}$ subsystems. For example, what are the differences between industrial and government research on similar problems in agricultural engineering or in the utilization of agricultural products? How does research in veterinary medicine compare with that in human medicine? Using a model like that sketched here may help in the design of such research.

\section{Conclusions}

Our exploration of some society-wide $\mathbf{R}$ and $\mathrm{D}$ institutions suggests certain general conclusions. First, $I$ think it is evident that $R$ and $D$ includes a variety of nationwide institutional systems which are not only descriptively different but also functionally different in the patterns of $R$ and $D$ they generate. Second, it appears possible to develop models of the operation of these systems analogous to the models that economic theory provides for the competitive price system and its variants. Third, such models would be useful in guiding empirical research, in explaining the directions taken by $R$ and $D$, and in evaluating the efficiency of alternative institutional arrangements for the performance of different $\mathrm{R}$ and $\mathrm{D}$ tasks.

Viewed more broadly, this paper has tried to apply the general approach of economics to the analysis of the organization and operation of institutional systems which differ considerably from those usually studied by economists. In this respect, it is similar to the work of Downs and Dahl and Lindblom on politico-economic institutions ${ }^{37}$

${ }^{37}$ Anthony Downs, An Economic Theory of Democracy, New York, 1957 and Robert A. Dahl and Charles E. Lindblom, Politics, Economics and Welfare, New York, 1953. 
and to the work of Simon on hierarchic formal organizations. ${ }^{38}$ The work of these writers suggests that it may be possible to develop theories that will enable us to explore the relations between (1) organizational structure, (2) type of task, (3) environmental conditions, and (4) task performance for a wider variety of institutional arrangements than are usually considered in economic analysis. It seems to me that the study of $\mathrm{R}$ and $\mathrm{D}$ provides both an incentive and an opportunity for broadening still further our knowledge of alternative institutional systems for the performance of social tasks.

\section{COMMENT}

\section{JOSEPH J. SPENGLER, Duke University}

Robert Merrill focuses attention upon the manner in which $\mathrm{R}$ and $\mathrm{D}$ is organized and directed within those subsystems of our societal system in which nonmarket forces play a major role and actual and prospective monetary profits supposedly play a relatively small part. Two types of subsystems are examined: theoretical science, in which practical application is not emphasized, and applied science, in which the major emphasis is put upon practical application (as, for example, in the fields of medicine, agriculture, and engineering).

It is assumed that, within each of these subsystems, the direction given to inventive activity depends very largely upon three conditions: (1) the alternatives considered; (2) the consequences associated with each alternative; and (3) "the 'preferences' or 'values' used to judge the desirability of the various alternative-consequence combinations." Attention is focused upon the last of these three presumably because, in the absence of a monetary common denominator to measure gross costs and gross benefits, some sort of indicator, albeit ill-defined, is required if one is to choose among alternatives. By contrast, the management of a business firm, when confronted by alternatives with which consequences are associated, usually would attempt to translate both alternatives and consequences into continua of estimated monetary costs and estimated monetary returns. Having allowed for the uncertainties involved, it would then choose an alternative and pursue it roughly up to the point where its pursuit paid no better than that of any other available choice. By such action the business firm would maximize its return above costs, given the inputs at its

\footnotetext{
${ }^{38}$ James C. March and Herbert A. Simon, Organizations, New York, 1958.
} 
disposal and the time horizon in terms of which decisions affecting profits are made. Of course if, as organization theory postulates, the "welfare function" of the firm includes other elements besides those immediately affecting net return over cost, the management would take these elements into account also; nonetheless its assessment and balancing of alternatives and consequences would run predominantly in terms of monetary costs and benefits.

It seems to be assumed that the set of alternatives available for consideration is essentially given. There is not much allowance, therefore, for the fact that decision makers, by their current actions, can or will substantially alter the set of alternatives confronting them in the future. Consequently the analysis of decision making within the subsystems studied seems to run largely in terms of the short run and to be based upon the assumption that the decision maker cannot significantly modify the environment of alternatives to which he is responding.

I find myself hard pressed to put behavior within any of these subsystems on a par with behavior in a profit dominated economy. I cannot find in any of the subsystems a clear-cut analogue of the price system which serves to organize and equilibrate the profit dominated behavior of all the private business firms composing the economy. Nor do I find enough analogues to the business firm which continually acts to maximize profits or some more composite success indicator, given actual and prospective buying, selling, and accounting prices, together with the particular industrial setting in which it finds itself. Even though one postulates the alternatives present in a subsystem, one needs to identify the specific decision makers together with the constraints faced by each and the organizational arrangement that binds these decision makers into a subsystem and somehow distributes scarce resources among them in a manner making for the stability and perpetuity of the subsystem.

Before turning to Merrill's analysis of particular subsystems, several implications of his study should be noted. By definition, that part of the realm of theoretical science which is not dominated by profit seeking firms is largely removed from the control of market forces, subject to the constraint that virtually all of the inputs utilized in theoretical science are scarce and hence must be rationed. By definition, also, any practical-art realm is much more dominated by market forces than is any theoretical realm, for the tastes and demands which a practical art subserves are largely shaped by market factors and by a considerable 
awareness of the opportunity costs involved in any particular course of action. Of course, one subsystem of the practical art sort may be more shaped by market forces than is some other.

I turn now to Merrill's analysis of the direction of $\mathrm{R}$ and $\mathrm{D}$ within the realm of theoretical science. Control is exercised largely by scientists participating in the particular cultural traditions of science and bent upon promoting "the aims and values embodied in this tradition." Science is organized, not by prices, but by the "professional judgments of achieved and expected performance" which are based upon "culturally transmitted standards of scientific significance and value." The overriding standard is described as that of deepening our understanding of nature, or of maximizing our advance in knowledge. Accordingly, interest and resources tend to be shifted, at the margin, to fields of science in which something is happening, that is, to fields in which new findings or methods have given rise to "new and wider opportunities for achieving greater precision or profundity" and for extending an affected field's systematic relevance and increasing its intrinsic interest. "Practical interest" is a subsidiary source of attraction.

Unfortunately, Merrill does not present supporting empirical evidence but instead counts heavily upon M. Polanyi's arguments. $\mathrm{He}$ does, of course, note that European scientists set greater value upon purely academic science than do American scientists, presumably because of differences in cultural tradition. One might argue, however, that a comparative scarcity of resources for relatively expensive practically oriented research may also be influential; after all, such scarcity helps account for the relative importance, in poor countries, of more cheaply produced training in the humanities and legal science.

Three allocative levels seem to be involved, though Merrill does not specifically identify the inputs relevant at each level: (1) recruitment of scientists into a given field of science; (2) recruitment of practitioners in a given field of science into a particular area of that field; and (3) allocation of auxiliary inputs among the scientists engaged at any given time in the various fields and sub-fields of science. One must become a physicist (instead of an economist) before one can become a solid-state physicist and, having become a solid-state physicist, one must get the auxiliary inputs if one is to carry on effectively. The standards emphasized by Merrill seem to be most applicable at level (3); they are not very applicable at level (1), and only modestly so at level (2). In any event, the comparative availability of funds (or 
resources) for remuneration and research will have much to do with whether a college graduate commits himself to some given field of science; it will also affect his choice of a specialty. One might discover the allocative forces operative by sampling and classifying scientists by major scientific category, specialty, age, type of institution with which connected, interspecialty shifts (if any), and principal reasons for choice of major category of science and of specialty within it. I incline to the view that awareness of differences in economic prospects, together with the ready availability of opportunities for advanced study (which also are economically determined), has much to do with the choice made.

The standards emphasized by Merrill seem most applicable at level (3) and within given fields. Even so, their influence is subject to restriction. When funds are not earmarked for particular fields, a certain amount of conventional egalitarianism affects their allocation; it is considered "unfair" to give "too much" to certain fields even though a strong case may be made for so doing. When funds are earmarked, activities tend to expand most rapidly in those areas in which earmarked funds expand most rapidly. In either situation it is likely, of course, that the amount of support given particular kinds of projects will be greater than otherwise if the instruments these projects produce are likely to be of use on other projects; then investment in the former set of projects results in external economies.

In the second part of his paper, Merrill examines research and development in terms both of its application to the solution of specific problems and of its use in the general improvement of a practical art. Three practical arts, medicine, agriculture, and engineering, are examined. Criteria of practical usefulness are held to operate in the field of medical research as well as in that of government-sponsored agricultural research, particularly in the selection of specific problems for solution. This is true also in engineering but in that field one also finds a considerable institutionalization and utilization of resources to improve engineering in general, seemingly more than in the field of medicine which draws upon a larger number of specialized sciences.

Within the field of medicine the direction given research is dominated by professional standards incorporated in the tradition of medical science; it is in light of these standards that the comparative importance of medical needs and the degree of their satisfaction is assessed. Because findings are promptly publicized they are expeditiously evaluated, as are the research techniques, and the like, associ- 
ated with them. Even so, nonscientific determinants may also be operative; for example, the attitudes of patients sometimes affect applied medical research and the same is true of foundation financing, be it rational or otherwise. It is questionable, of course, whether standards used to define what is good medical practice have much to do with how investigators are recruited or with how resources are allocated among them. The prospect of economic advantage probably plays a major part in determining what research is undertaken. Careful inquiry might disclose what particular tastes and interests animate those whose funds help give direction, be it economically warranted or not, to medical research.

Applied research and development in the field of government sponsored agricultural research is largely controlled by governmental agencies. The criterion of prospective economic usefulness appears to determine what is to be done. It is not disclosed how this criterion is applied. Nor is it disclosed whether the criterion of usefulness is better defined and more closely conformed to in this field than in that of medical research in which, at least until recently, the role of government has been small.

Engineering is described as less influenced by scientific specialists than is medicine and, also, as far more completely under the influence of profit seeking firms, inasmuch as they employ most of the engineers engaged in $R$ and $D$. Some support is given to basic research, principally by larger firms and a few research-oriented engineering schools. It is noted, however, that the increasing capacity of theoretical engineering research to give rise to widely applicable results as well as to contribute to the general improvement of engineering is making for greater support of basic research.

Merrill does not report which of the three practical arts considered is most closely oriented to the market and hence most under its influence. Engineering appears to be the most market-dominated of the three, with government-sponsored agricultural research second, and medical research third. In the field of engineering, the market seems largely to determine how much money is available for research and the uses to which it is put. In the field of agricultural research, the market influences what is done in far greater measure than it influences how much is done. The same is true of medicine but to a lesser extent.

In each of these three fields one might endeavor to determine the extent to which the market governs what research is undertaken, 
and then seek to explain the residuum in noneconomic terms. This approach, if it could be carried out, would provide us with a better estimate of the relative importance of nonmarket factors than we presently have. It might also disclose the role of market forces to be quite important even when nonmarket forces are supposed to be playing the major role. After all, as Pareto and Marshall and others have suggested, market forces sometimes resemble icebergs in that much of their influence is exercised from submerged situations and, hence, hidden from superficial examination.

The basic problem with which Merrill deals requires further analytical clarification. (1) Each subsystem, together with its allocative machinery, must be defined and bounded. (2) Values must be separated into those present within a subsystem (where they may constrain the operation of the allocative machinery) and those present outside the subsystem. The values outside the subsystem must be classified in turn into those which are largely shaped within the market (e.g. ordinary consumer tastes) or outside the market (e.g. those that generate dispositions to supply funds for defense and offense, space travel, specialized medical research, etc.). (3) The sources of the personnel and other resources available to any particular subsystem must be carefully identified, as must the circumstances which govern this availability through time. (4) The levels at which the allocation of personnel and inputs takes place need to be differentiated.

Given analytical distinctions of the sort indicated, it will be found that most of the personnel and resources available to any of the subsystems treated by Merrill flow in from the outside. They do so largely in consequence of values generated outside the subsystem, either within the market or outside the market. Furthermore, even when these values have been originated and organized outside the market (e.g. by the action of special interest groups expressed through government agencies or private foundations), their realization is accomplished through the market. Funds are made available and individuals and auxiliary equipment are "hired" to accomplish the objective ends to which the values point. These individuals and equipment could not otherwise be engaged to objectify the values in question; for only very rarely will individuals engage in a line of activity irrespective of the remuneration offered and the other alternatives available. Moreover, even within a subsystem, material advantage will be largely counted upon to attract men and materials to one sector and from others. In sum, advocates of given courses of research 
action must rely largely upon the use of material rewards; for, as Rochefoucauld implied, material self-interest usually swallows up virtue. What is most in need of explanation is why certain courses of action come to be preferred by given individuals and how those individuals go about the business of raising the material means with which to induce competent persons to implement such courses of action. 